\title{
HOW DO UPBRINGING AND EXPERIENCES AFFECT JAPANESE STUDENTS' ATTITUDES ON FOOD WASTE?
}

\author{
TOMOKO OKAYAMA ${ }^{1} \&$ KOHEI WATANABE ${ }^{2}$ \\ ${ }^{1}$ Taisho University, Japan \\ ${ }^{2}$ University of Southampton, UK
}

\begin{abstract}
A questionnaire survey was conducted to Japanese university students, on their part-time job experience with food establishments, current and past experience and habits relating to food, and their opinions on food waste. Survey results indicate that instructions at home had the strongest influence in building up students' attitudes against wasting food at various settings. Instructions at school lunches and taking environmental courses in university contributed to a lesser degree. On the other hand, experience in a food-related job made students more positive about current practice on wasting food. Analysis results also indicated a connection between concerns on "best before" dates and support on the current practice of wastage.

Keywords: food waste, questionnaire survey, Japanese students, formation of attitudes, education.
\end{abstract}

\section{INTRODUCTION}

\subsection{Food waste: classification and its extent in Japan}

Not all food that is produced for human consumption ends up in people's stomachs. Some food items will be destined to non-food use, some food is depreciated during transport and storage, some parts of food are actually not edible and will be removed before eating. Even the purely edible fraction is not completely appreciated - a significant part of that is disposed of along the food supply chain, or destined to the bin by the consumer. Different institutions use different terms for various part of food that was lost or wasted. Fig. 1 is an attempt to making a correspondence between terms used in Japan and that in English. In the UN/FAO definition, "food waste" is a subset of "food loss" [1], [2], while in Japan the term "food loss" (shokuhin rosu) is used to indicate the wastage of edible part of food, thus a subset of "food waste" (shokuhin haikibutsu), which includes the inedible parts. UN/FAO in their official definition do not include the inedible parts in either food loss or food waste [3], however Tayyib and Golini [4] state that non-edible parts are included in their data for food availability and for food losses.

FUSIONS explicitly includes inedible parts in their notion of "food waste", and their definition is basically equivalent to the Japanese one [5]. WRAP UK [6] describes the waste of potentially edible food as "avoidable food waste", while the inedible parts are "unavoidable food waste". A totally different definition have been proposed in the context of Sustainable Development Goals (SDG) 12.3 which is based on monetary value of food [7]. SDG12.3 calls for halving the per capita global food waste at the retail and consumer levels, and for reducing food losses along production and supply chains [8]. However the indicator for this item is categorised as Tier 3, which means that no internationally established methodology or standards are yet available for the indicator [9].

According to the Ministry of Agriculture, Fishery and Forestry (MAFF) Japan's statistics relating to the food recycling law [10], total "food waste" including inedible parts in 2014 was $27.75 \mathrm{Mt}$, of which 8.22 Mt originated from households, and 19.53 Mt from commercial sources. This accounts to $33.5 \%$ of crude food supply of Japan. The focus of this study is on 


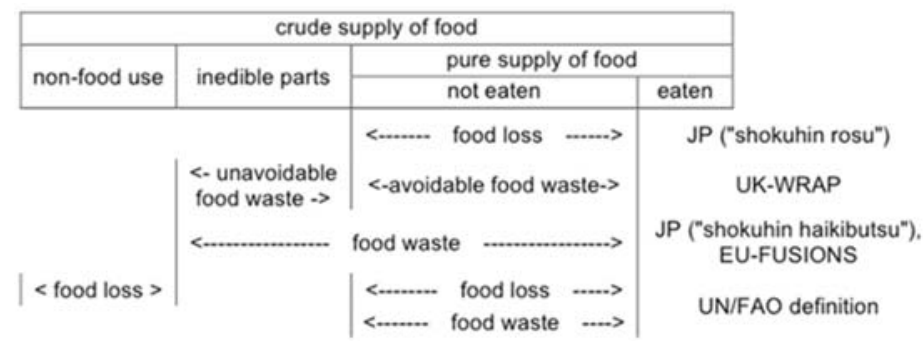

Figure 1: Different notions of "food loss" and "food waste" [1]-[6], [10].

the "food loss" in the Japanese notion, which is avoidable or potentially edible food waste. These are items such as unsold or expired food and plate leftovers and they add up to 6.21 $\mathrm{Mt}$, of which $3.39 \mathrm{Mt}$ is of commercial origin and 2.82 Mt household. $34.3 \%$ of food waste from households (i.e. kitchen waste) is deemed potentially edible (there are other sources that indicate as much as $50 \%$ of kitchen waste is potentially edible [11]).

MAFF classifies avoidable food waste into the following: (1) depreciation of food in transport and storage (postharvest loss); (2) unsold or expired food; (3) plate leftovers; and (4) excessive removal of inedible parts. Avoidable food waste from wholesalers and retailer amounts to $1.27 \mathrm{Mt}$, the edible fraction of food waste from food service (restaurants, cafes, etc.) $1.94 \mathrm{Mt}$.

\subsection{Japanese students and food waste}

Food related businesses such as fast food restaurants and convenience stores provide large part-time job opportunities for students. A large number of students take up part-time jobs while attending university. There are more than 7,000 convenience stores in Tokyo prefecture alone. Most convenience stores in Tokyo run $24 \mathrm{~h} / 7$ days, and many fast food chains operate into small hours. It is said that their operation relies on part-time labour provided by students [12]. Especially students that are not enrolled in top ranked universities tend to take up those food related work at a relatively low wage of ca. USD 8.4/hour [13]. Many food-related establishments throw away a large amount of food as business practise [14], [15]. It is likely that students witness such scenes, or actually be engaged in the disposal operation. Some students report to teaching staffs in the university that they were shocked to see a massive amount of food being disposed, while they are aware that there are a significant number of people in the world suffering from hunger [16]. Fukuoka at the Osaka Institute of Technology initiated the "Food Loss Shock Study Group" (hereafter "study group") in 2015. In the same year, the study group conducted a questionnaire survey among students at four universities (Osaka Institute of Technology, Osaka Industrial University, Oberlin University, Taisho University), to investigate the students' attitudes and responses to wastage of food [17].

This paper is based on the results of the questionnaire survey in Taisho University where the first author was affiliated to, and in Teikyo University which was the affiliation of the second author who is not a member of the abovementioned study group. The main objective of this survey was to identify what factors and experiences in their upbringing and education shaped the students' attitudes and behaviour towards food wastage. The questionnaire sheet for the study group's 2015 survey was used as the basis of this survey. The authors modified it with additional questions, and alteration on the conditional branching of questions, to serve the research objectives (Appendix 1). 
There exist many studies involving questionnaire surveys on people's attitudes and behaviour on food waste, including those targeted on students [18], [19]. The novelty of this study is that the authors focused on the upbringing and educational factors on the formation of attitudes. The extent how far this study with students in Tokyo can be generalised requires further verification, but it is expected that the findings here would provide useful viewpoints and a basis for comparison with groups with different cultural and socio-economic backgrounds.

\section{METHODOLOGY}

\subsection{Design of survey sheet}

A questionnaire survey consisting of 40 questions (including seven questions on personal attributes, such as eating and cooking customs at home, and experience of part-time jobs including involvement in mass disposal of food at work) was prepared. Table 1 shows the content of the survey (English translation of the survey sheet is shown in Appendix 1). Some questions were only applicable to students with an experience of part-time jobs. This was to observe the effect of the experience of mass food disposal, e.g. change in attitudes, which was the focus of Fukuoka et al. [17].

\subsection{Survey subjects}

Surveys were conducted in Taisho and Teikyo Universities, in July and September 2015. Taisho University is located in central Tokyo, while the Hachioji Campus of Teikyo University where the survey was carried out is located in the suburb, $35 \mathrm{~km}$ west of central Tokyo. Both Universities are ranked mid to low in terms of school grades of admitted students, hence they are the major source of temporary workforce for the food businesses, as mentioned in Section 1.2. Printed survey sheets were distributed, filled in and collected at university classrooms. Altogether 406 valid responses were obtained. In terms of university affiliation, 294 at Taisho, and 112 at Teikyo. The gender ratio was 59\% (male): 41\% (female). The summary of responses is shown in Table 2.

In this survey, in addition to conventional personal attribute information such as age and gender, an additional attribute, "environment" and "non-environment" students was created, with the hypothesis that the degree of interest in environmental issues may affect the student's attitudes on wastage of food. At Taisho University, undergraduate students enrolled in the environment policy major (course) were identified as "environment" students. The "nonenvironment" group in Taisho consists of undergraduate students majoring in variety of other humanity subjects. Since Teikyo University does not have an environment related major, undergraduate students attending a lecture series on environment were tagged as "environment". They were enrolled in different social sciences and humanity departments (e.g. economics, law, literature). The "non-environment" sample in Teikyo consists of undergraduate students in the sociology department, taking social statistics or programming practicals (selection of classes was due to logistic factors).

\section{ANALYSIS}

\subsection{Attitudes to wastage of food}

Cross tabulation and statistical testing were conducted. The authors' interest is how the attitudes towards food waste are affected by students' upbringing and experiences. Four 
Table 1: Contents of survey sheet.

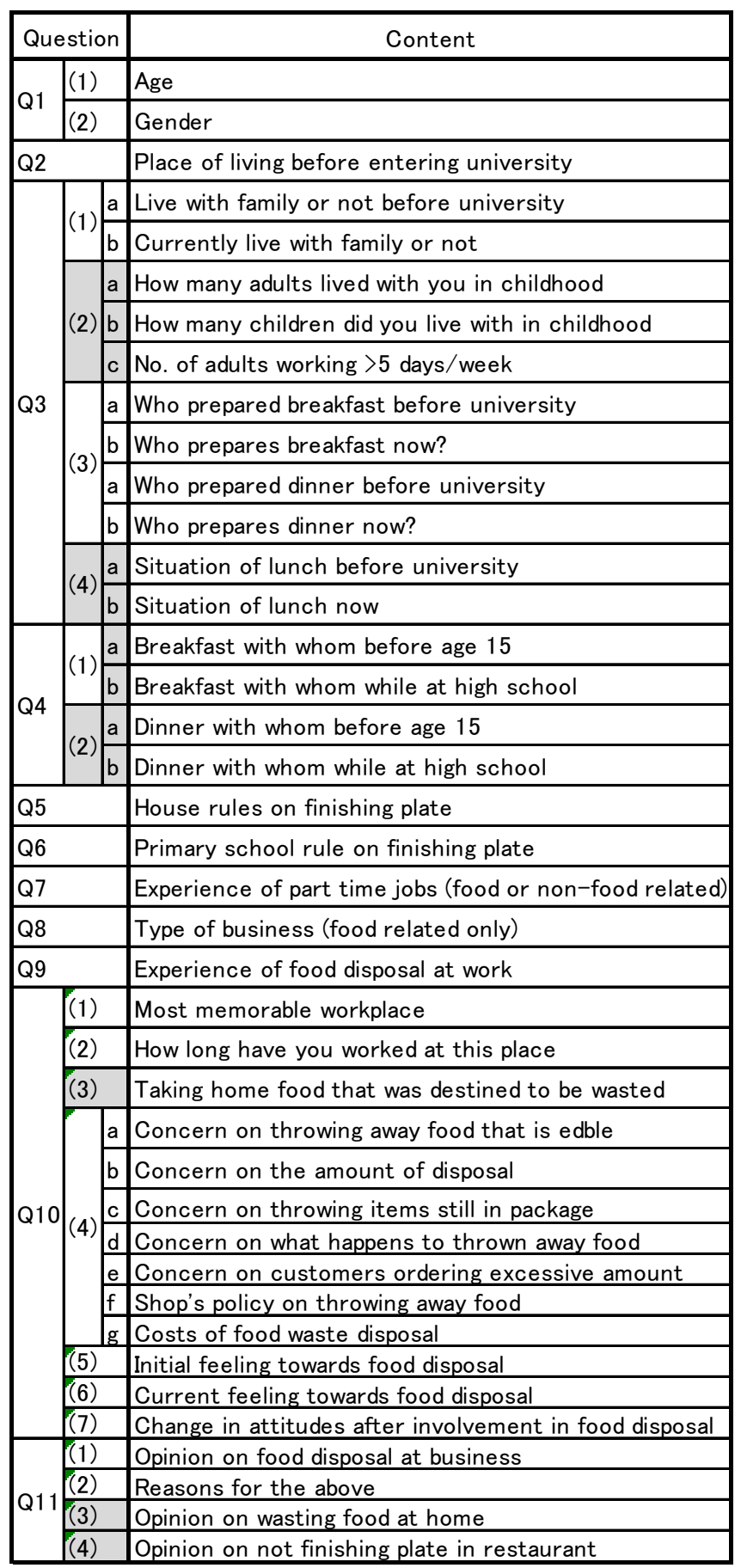

* Questions in shades are those added to Fukuoka et al. (2016) by the authors. 
Table 2: Summary of survey subjects.

\begin{tabular}{|r|l|r|r|r|r|r|r|}
\hline \multicolumn{2}{|r|}{ age } & 18 & 19 & 20 & 21 & $22+$ & Tot. \\
\hline \multirow{2}{*}{ Taisho U Unviron't } & 29 & 20 & 27 & 25 & 11 & 112 \\
\cline { 2 - 8 } & non-Env & 65 & 77 & 37 & 1 & 2 & 182 \\
\hline \multirow{2}{*}{ Teikyo U Unviron't } & 10 & 20 & 20 & 7 & 4 & 61 \\
\cline { 2 - 8 } & non-Env & 0 & 27 & 18 & 3 & 3 & 51 \\
\hline \multicolumn{2}{|c|}{ Total } & 104 & 144 & 102 & 36 & 20 & 406 \\
\hline
\end{tabular}

questionnaire items as dependent variables were identified. They are attitudes towards food waste by businesses (Q11-1), by oneself at home (Q11-3), at restaurants (Q11-4), and by others (customers) at restaurants (Q10-4-e) (Fig. 2).

In Q11-1, responses (3) (should be discouraged) and (4) (should be prohibited) were classified as attitudes against food waste. In Q11-3 and 4, response (3) (uneasy with wasting any amount or type of food) are tagged as such. For Q10-4-e, the authors compared those who are (1) very much or (2) somewhat concerned with customers ordering excessive amounts of food, against the rest ((3), (4) and (5)). The authors also created a composite boolean variable "against food waste in all settings" which takes the value of 1 when responses for Q11-1,3,4 and Q10-4-e above indicate anti food waste.

The independent variables were as follows (see also Table 1): "environment"/“nonenvironment", gender (Q1-2), current situation of housing (Q3-1b), presence of non-full time working adult (Q3-2AB), presence of more than three adults (extended family) (Q3-2A), currently cook own dinner (Q3-3), eat breakfast alone at primary school age (Q4), eat dinner alone at high school age (Q4), instruction (discipline) at home on finishing plate (Q5), instruction at school lunches (Q6), experience of food disposal at work (Q9). Some questionnaire items were not included as independent variables because of lack of variance (i.e. the responses were dominated by one choice).

Regarding Q9, out of 410 students, 85\% $(n=348)$ had experienced part-time jobs, $64 \%$ $(\mathrm{n}=263)$ in food related businesses. Of which, the restaurant (food service) sector had the largest share with $58 \% .81 \%(\mathrm{n}=215)$ of those on food-related part-time jobs were involved in food disposal operations. This is $52 \%$ of the total sample.

\subsubsection{Wastage of food by businesses}

Most respondents accepted that some wastage of food by businesses is inevitable. Only ten respondents chose that wasting food at businesses is something that should be prohibited. 139 was of the opinion that it should be avoided, while 173 thought that it is a normal thing

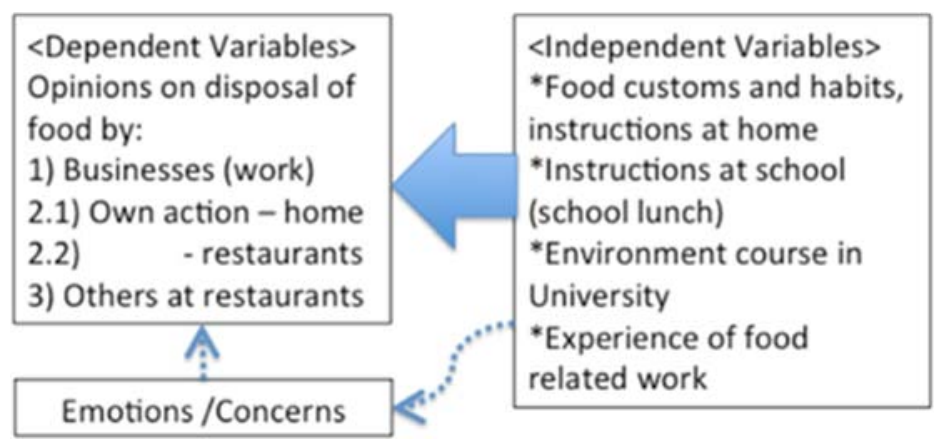

Figure 2: Dependent and independent variables. 
to do, and another 80 stated that it is a necessary thing to do. The authors grouped the former two responses (should be prohibited/avoided) as "against food waste" and carried out chi squared analyses on $2 \times 2$ cross tabulations with the independent variables. The authors also treated the response number ( 1 (necessary) to 4 (prohibited)) as a measure of resistance against food wastage and carried out t-tests on the difference of average values. Q5 "Discipline on food at home" (Scolded for not finishing food) had the highest significance on the variance on attitudes towards food wastage by businesses $(\chi 2=6.17, \mathrm{p}=0.013 / \mathrm{t}=2.675$, $\mathrm{p}=0.008$, Fig. 3). Also those with no experience of food disposal at work (Q9) tended to be more against food wastage by businesses $(\chi 2=4.77, p=0.029 / \mathrm{t}=1.990, \mathrm{p}=0.047$, Fig. 4).

\subsubsection{Reasons for opinions on food wastage at businesses}

In question Q11-2, the reasons for the opinions selected above in Q11-1 were asked. The results are summarised in Fig. 5. "Necessary rule for maintaining food hygiene" was the most popular reason chosen by those who are affirmative about food wastage (35\%). This was especially the dominant reasoning for those with experiences of food disposal at work $(\mathrm{p}<0.01)$. Those who were affirmative to food wastage also selected as a reason, that food waste is recycled $(11 \%)$ or donated $(6 \%)$, however this was higher with those with no experience of disposal at work $(\mathrm{p}<0.01)$. Probably those with experience are aware that in most cases food waste is just treated as non-recyclable waste, and not donated or recycled. The opportunity of staff taking home what is destined for waste $(11 \%)$ also contributed to the acceptance of food disposal. Interestingly, those with no experience in food disposal at work selected this item almost as much as those with experience, while only a fraction of those who actually took home expired food chose this as a reason (see Section 3.2 for further discussion on this).

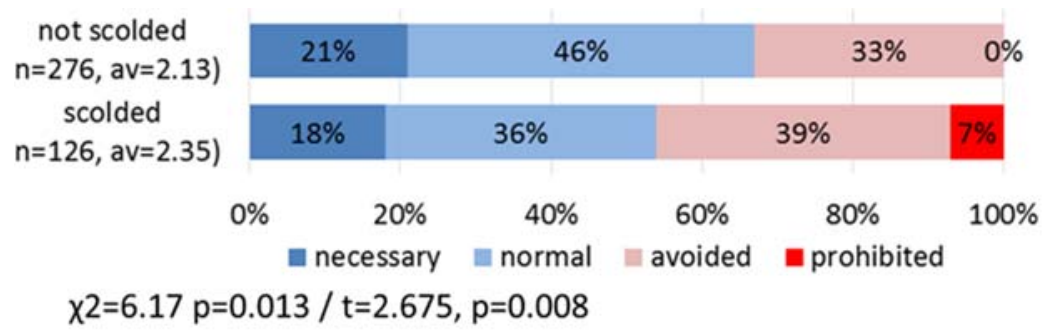

Figure 3: Discipline at home and opinion on food wastage by businesses.

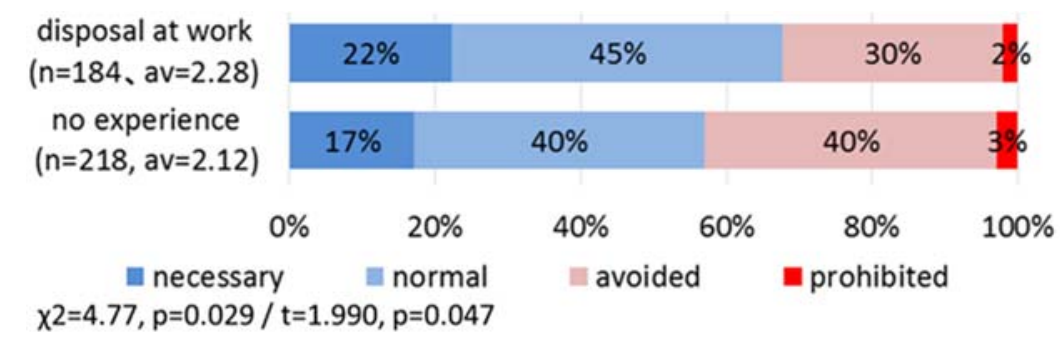

Figure 4: Opinions on food wastage by businesses, according to work experience. 


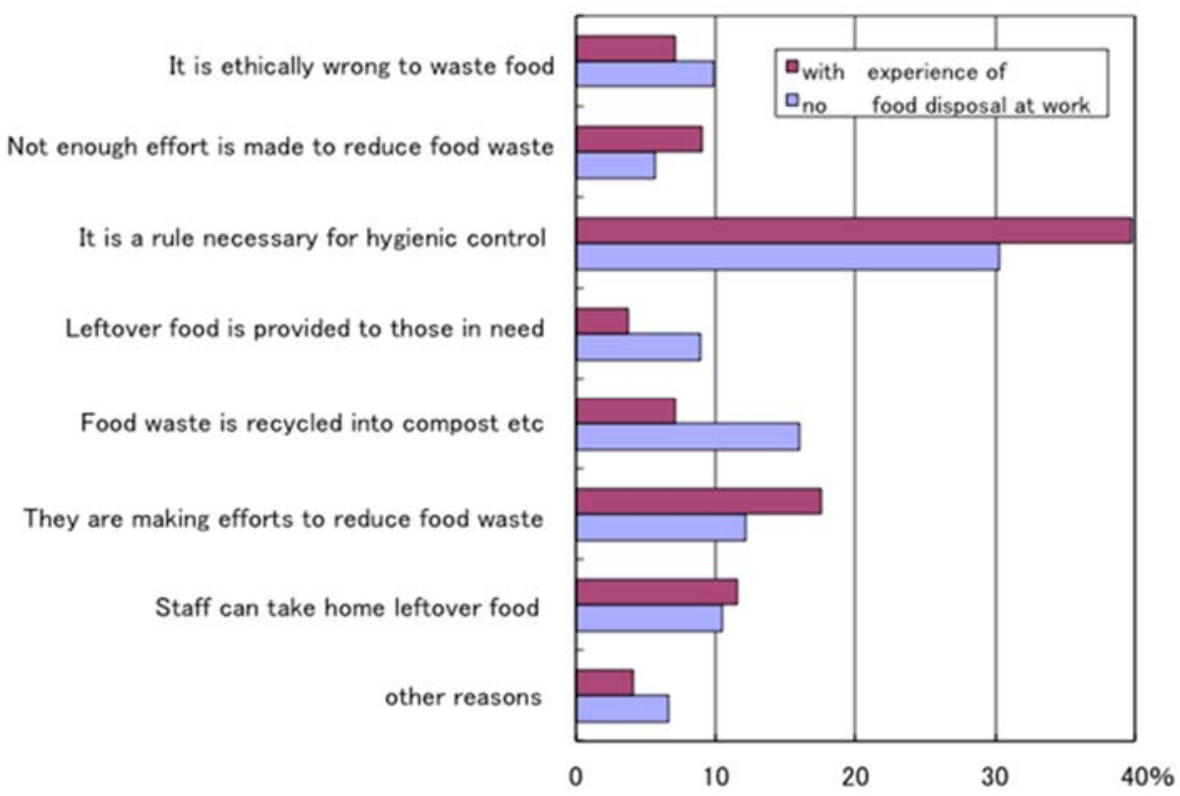

Figure 5: Reasons for opinions on food wastage by businesses.

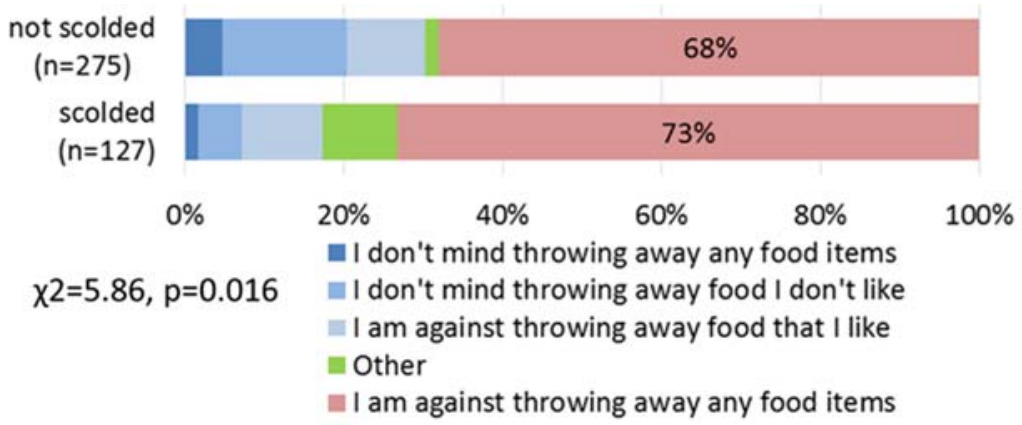

Figure 6: Attitudes towards wastage of food at home.

\subsubsection{Wastage by oneself}

\subsubsection{Wastage of food at home}

$72.4 \%$ (280 out of 402 ) of the respondents expressed uneasiness to wasting any amount of food at home, while 50 respondents did not mind leaving food that they don't like, and 15 were of the opinion that it is okay to leave any type or amount of food. Two independent variables turned out to have a statistically significant relationship with this response $(p<0.05$ in chi squared tests). Those were "scolded for not finishing food at home" $(\chi 2=5.86, p=0.016$, Fig. 6), and the "presence of any adult at home not in full time employment" $(\chi 2=4.44$, $\mathrm{p}=0.035$ ). "More than three adults at home" had a p-value of 0.052 . Basically, adults" supervision appears to nurture the attitude not to waste food at home. There was a difference 
in gender as well. Females tend to be more concerned about wasting food at home, although not statistically significant at the $5 \%$ level $(\mathrm{p}=0.068)$.

\subsubsection{Not finishing own plate at restaurants}

The proportion of respondents finding it uneasy to leaving any type or amount of food at restaurants was $57.6 \%(216 / 401)$, much lower than for that at home. 97 respondents were against leaving a large amount of food. Nine indicated that they did not mind about wastage. The issue of food waste does not appear to be a matter of money; "depends on the price of the item" was the least popular with only seven responses. Here again, "scolded for not finishing food at home" had a strongly significant effect on the responses $(\chi 2=18.6, p<0.001$, Fig. 7). "Environment/non-environment" was also significant $(\chi 2=8.08, \mathrm{p}=0.004)$.

\subsubsection{Waste of food by others at restaurants}

This item was asked only to those with experience in food-related work, as they are more likely to come across customers that order excessive amount of food and to witness that the leftover goes to waste. The total applicable respondents were 215 , as opposed to $n=402$ in Sections 3.1.1 and 3.1.2.

No independent variable turned out to have a significant effect on response to this question. Nevertheless, instructions at school lunches had the strongest influence $(p=0.18$, Fig. 8). This was stronger than "scolded at home for not finishing plate" $(\mathrm{p}=0.23)$ which was prevalent in the above sections. This can be due to the fact that the setting and context of school lunches are more similar to the situation at restaurants compared to eating at home. In addition, instructions at schools may have provided a sense of moral norm that wasting food should not be a matter of personal choice.

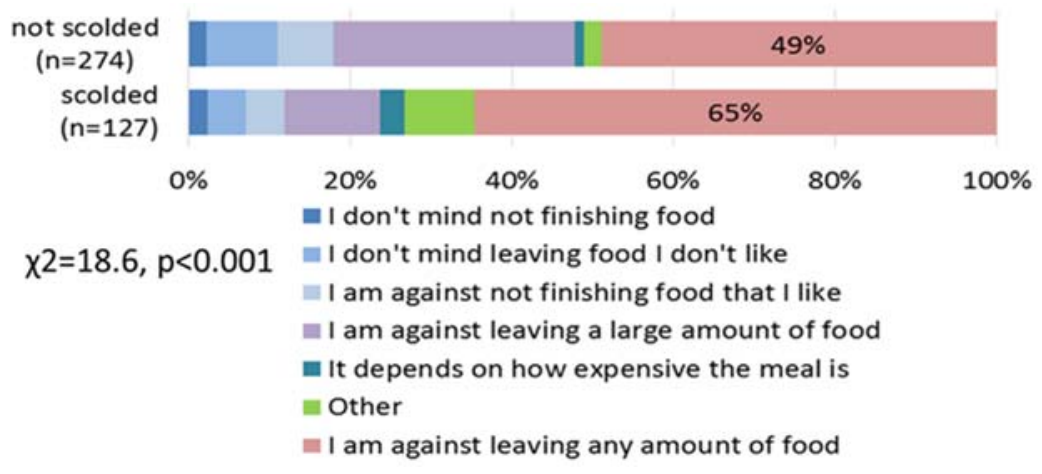

Figure 7: Attitudes towards not finishing plates at restaurants.

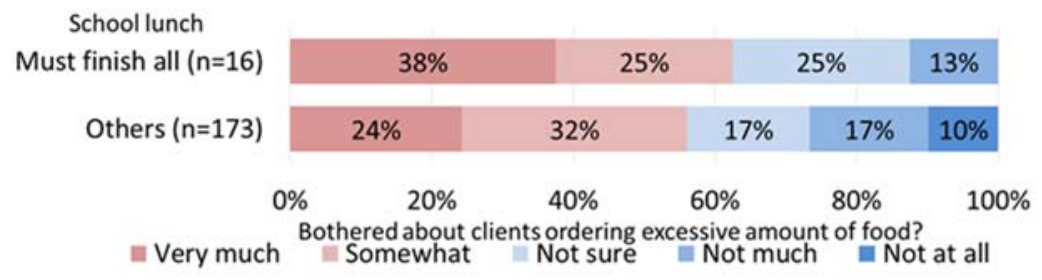

Figure 8: Instruction at school lunches and attitudes to clients at restaurants. 


\subsubsection{Wastage of food in all settings}

Twenty nine (13.6\%) out of 214 applicable respondents expressed uneasiness or objection to wasting food at all four situations (by oneself at home and at restaurants, by businesses, and by customers at restaurants). Only one independent variable turned out to have a statistically significant relationship with the "against food waste in all settings" attitude, namely Q5 scolded if didn't finish food at home $(\chi 2=9.39, \mathrm{p}<0.005)$. Another factor that gave a positive tendency to this attitude was enrolment in environment courses or lectures at university $(6.7 \%$ points difference, although not statistically significant). Variables such as gender or instruction at school lunches did not make a notable difference on overall attitudes to food waste.

\subsection{Analysis of emotions}

\subsubsection{Education, emotions and attitudes}

Q10-5 asked about the feeling or emotion when the students first witnessed food disposal at work. The respondents were to select up to two emotions from the list of nine, including "no significant feeling" (did not feel anything) (Fig. 9). "Surprise" (35\%) was the most prevalent choice. "Uneasiness", "no emotion" and "sadness" were each chosen by about $25 \%$. Theoretically there are 81 combinations in the responses, but the authors have classified them into (1) surprise only, (2) uneasy only, (3) no feeling (only), (4) sadness or anger (+ any other emotion), (5) positive feeling (excitement and happiness + any other emotion), (6) others. This is because "surprise" is rather value neutral, "uneasy" is a weaker feeling and not as specific as compared to "sadness" or "anger", which were considered as firm negative emotions.

The authors assumed that feelings or emotions can be a driver for attitudes or opinions, and conducted cross tabulations. However, even "sadness or anger" did not have any significant relationship with the attitudes to food wastage at various settings as analysed in Section 3.1 (Fig. 10). Nor did these feelings and emotions have any significant relationship with education and upbringing factors such as enrolment in environment courses or being scolded at home for not finishing ones plate (Fig. 11). This suggests that education have little influence on emotions, and emotions have little influence in attitudes or opinions. Emotions can just be first impressions, not triggering any further thoughts.

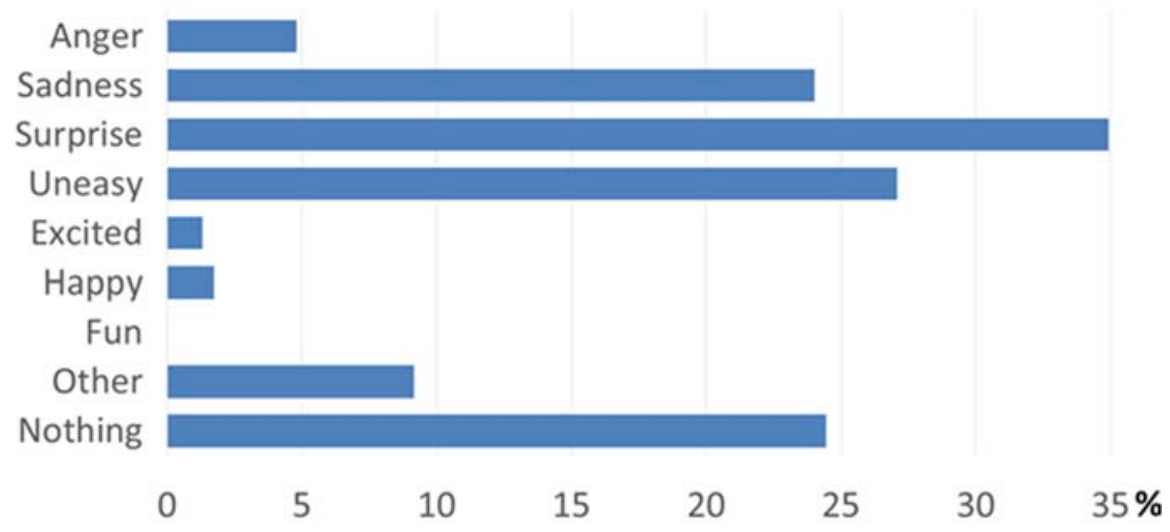

Figure 9: Emotions at initial experience of food disposal at work. 


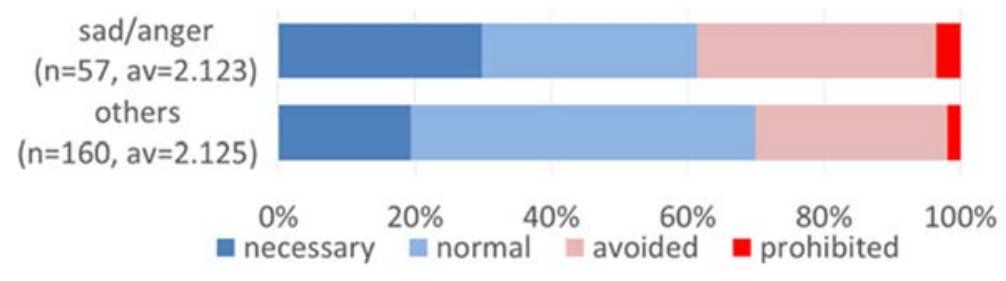

Figure 10: Emotions and attitudes towards food wastage by businesses.

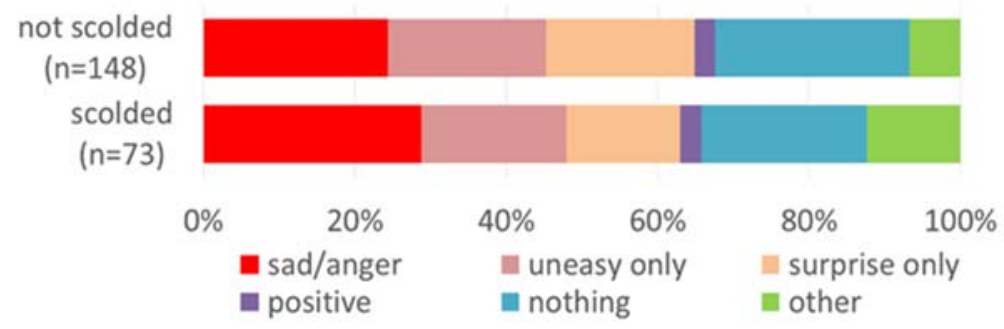

Figure 11: Discipline at home and emotions.

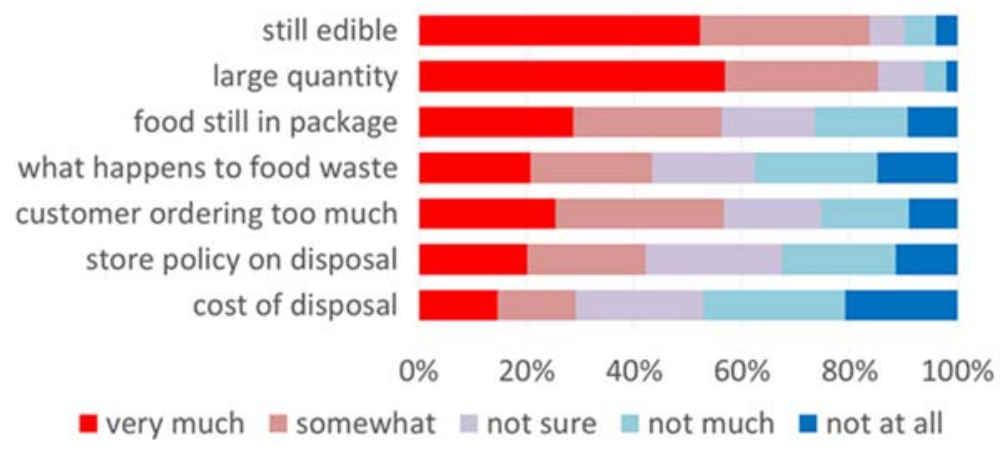

Figure 12: Concerns on food disposal by businesses.

3.2.2 Emotions and aspects of concern

In Q10-4 (concerns relating to food disposal at businesses), more than half of the students who experienced mass disposal of food were "very much concerned" about the fact that the food they throw away food is still edible, and also that they throw a large amount. Smaller concern was indicated on what happens to the disposed food, or the cost of disposal (Fig. 12).

Emotions did have relations with response to Q10-4. Those who experienced sadness or anger are significantly more concerned that the disposed food is still edible (Fig. 13), the quantity of disposal, what happens to the disposed food, and the cost of disposal. On the other hand, the sad and angry were not significantly more concerned with shop's policy on food disposal, which generally received a low concern (Fig. 14). It appears that the students take these policies as acceptable or given. Some of the students have concerns with the practise of food disposal, but not as far as to form a rigid opinion on it. 


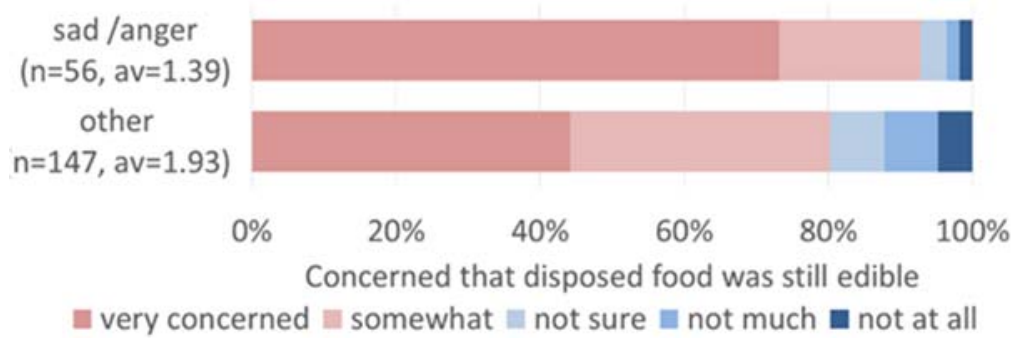

Figure 13: Emotions and concern that food waste is still edible.

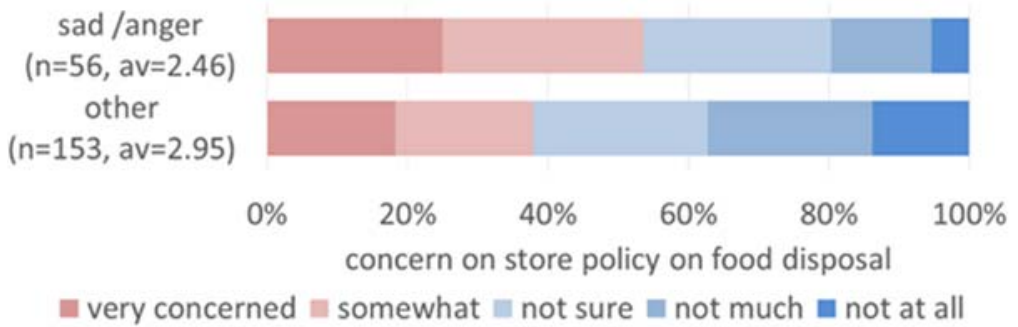

Figure 14: Emotions and concern on store policy.

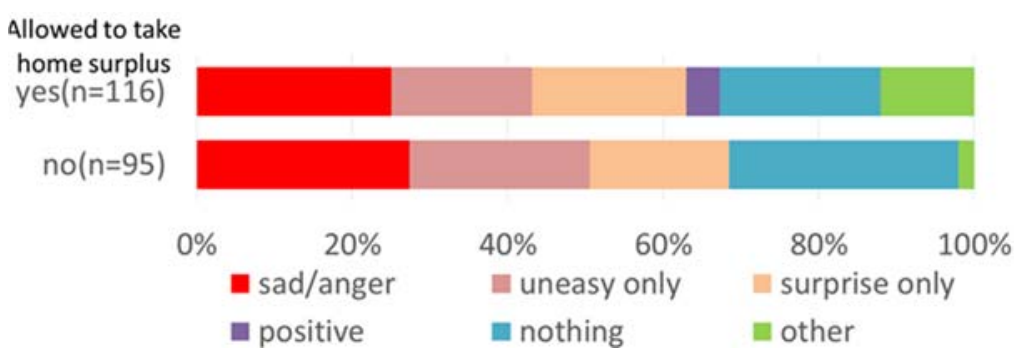

Figure 15: Taking home surplus and emotions.

\subsubsection{Positive emotions and the opportunity of taking home food that was destined to disposal}

There were a minority of respondents who were excited or felt happy. All those who had a positive feeling to food wastage had experiences of bringing home food that was destined to waste (Q10-3). However, only 5\% of those who could take advantage of wasted food indicated positive feelings, the rest $(95 \%)$ were negative or had no significant emotions (Fig. 15). In addition, being allowed to take home surplus did not affect students' opinions towards wastage by businesses (Fig. 16).

Together with the results in Section 3.1.1.1, it could be said that letting workers take home surplus or expired food can make people (including outsiders) less resistant to the current wasting practice, but it would not give much adverse incentive for workers not to make efforts on reducing food waste (they still feel bad to see food being wasted). 


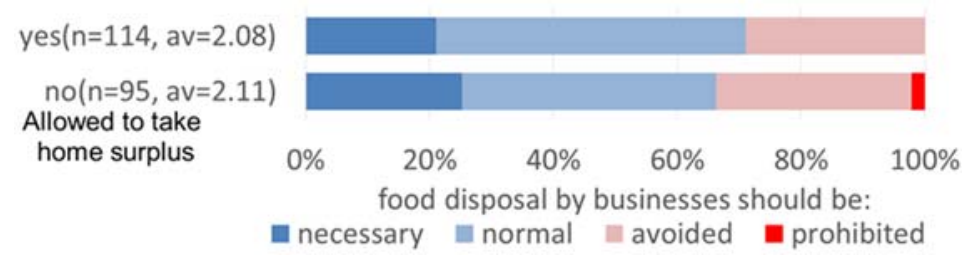

Figure 16: Taking home surplus and opinions.

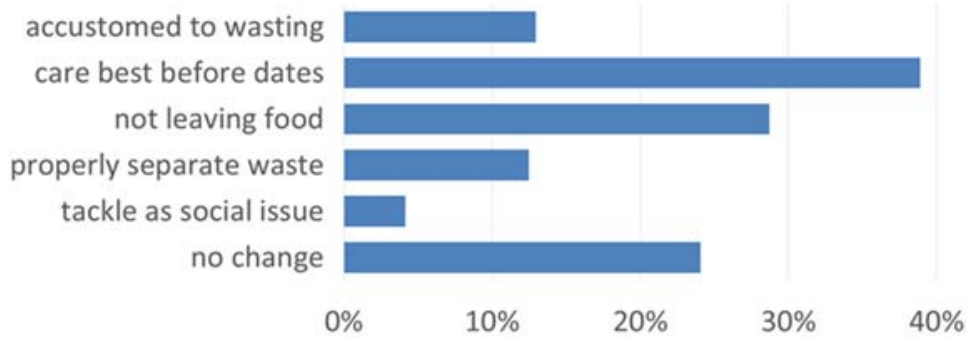

Figure 17: Changes after experiencing food disposal at work.

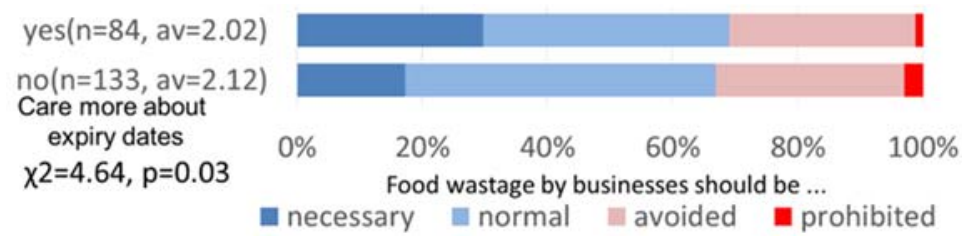

Figure 18: Caring more about expiry dates and opinions.

3.2.4 Changes in emotions over time

Q10-6 asked if the emotions selected in Q10-5 has changed over time with continuation of work. Most respondents currently feel the same as in the beginning (65\%), but $30 \%$ have a weaker or no feeling after working for a while. Only $4 \%$ have stronger feelings than in the beginning (Fig. 17). It is understandable that "surprise" only happens with the first encounter, and also as one gets used to the situation, negative feelings can fade.

3.2.5 Changes in attitudes and behaviour as a result of experiencing food disposal at work Regarding Q10-7 (changes in attitudes, multiple answers allowed), while 25\% expressed that their attitudes haven't changed with being constantly involved in disposing food (especially with those who "didn't feel anything" in Q10-5), 40\% became more concerned with expiry dates, $30 \%$ were more conscious on their own food wastage, and $13 \%$ stated that they lost the resistance against wasting food. Only a very small minority (4\%) were motivated to tackle with food waste as a social issue.

A cross tabulation between Q10-7 and Q11-1 (opinion on food wastage by businesses) was conducted. It turned out that those who became more concerned with expiry dates were significantly more supportive of food disposal practices in Q11-1 (it is "necessary" to dispose of food, Fig. 18). 


\section{DISCUSSION}

The above results showed that "scolded for not finishing food at home", i.e. food education at home, had the strongest effect on attitudes to food wastage in general. Probably, factors such as eating together with someone at home etc. are probably on the same vector, as adults can show role models on attitudes towards food, even if they didn't explicitly instruct.

On the other hand, instructions at school lunches did not turn out as statistically significant, although it showed supporting tendencies to attitudes against food waste (e.g. concern on clients ordering excessive amounts at restaurant). It could be pointed out that food education, such as instruction to finish everything on plate at schools in Japan is becoming increasingly difficult nowadays. There are now more children with allergies to various kinds of food, and there is the presence of "monster parents" who will misinterpret encouragement to finishing one's plate as corporal punishment - forcing to eat something against one's will. Naturally, teachers will be risk avert and not intervene on pupils habits with food (this is reflected in the survey results that students having experienced a rigid policy about finishing school lunches was rare). However, school lunches are seen as an important opportunity for food education [20], and parents expect a lot from it - even wishing to delegate their role of food education to schools [21]. Broader knowledge on the issues may also help; the survey results indicated that students taking environmental courses tend to have a more frugal attitude towards food (Sections 3.1.2.2/3.1.4 above). Having observed the disconnection between emotion, concern, and attitudes (Sections 3.2.1 and 3.2.2), as well as the tendency of taking disposal policies and best before dates as given, probably the most important role of education is to nurture the ability of formulating ones opinions when faced with experiences that trigger some kind of concerns or negative feelings.

Survey results indicated that those who are more concerned with "best before" dates tend to be more affirmative to food disposal by businesses (3.2.5). Also, many chose as a reason that food disposal by businesses is a necessary rule for hygienic control (3.1.1.1). It is reported that Japanese consumers tend to have almost an obsession with freshness and perfectness of food [14]. It is usual practice to divert the whole production lot to disposal when there is a minor defect on outer packaging, or a very small possibility of foreign objects (e.g. broken plastic parts of a processing machine) in a product. Some companies that did not follow this procedure were bashed in the media and/or boycotted by the public, although no actual damage to health had happened. Under the current situation, any effort to reduce food waste by businesses will most likely run the risk of having a bad reputation of being denounced, for example, for incompliance of standards. The projected financial savings by efficient use of food is far outweighed by the risk of losing business by ungrounded accusations.

As a breakthrough, a legislative initiative such as the French and Italian laws on mandating supermarkets to utilise all food that they handle (ban on disposal) would help in providing legitimacy for action on food waste reduction by businesses. Other legal provisions such as the "good Samaritan act" [22], or exemption for liability on food taken out of restaurant premises are crucial in getting businesses implement effective measures.

Hands-on experience with food, such as regularly cooking own meals also appeared to nurture attitudes against food wastage. Contrarily, another hands-on experience with food, throwing away food in a part-time job setting, seemed to create higher acceptance of food wastage, rather than raising critical awareness. Probably, being paid to do something gives a sense of authorisation for the action. Also, in general, people try to justify what one is made to do. Obedience is considered a virtue in Japan, and it is somewhat disappointing that the encounter with mass disposal of food, for most students, does not lead to anger or a perception that it is a social issue that needs to be tackled. 


\section{ACKNOWLEDGEMENTS}

The authors would like to acknowledge the efforts of Mr Yuma Nakahara (Taisho University student) who converted the collected survey sheets into an excel worksheet and conducted initial tabulations. The authors are also thankful to other members of the "Food Loss Shock Study Group" who let the authors conduct this spin-off research. This work was supported by JSPS KAKENHI Grant Number 15K12283 (leader: M. Fukuoka, Osaka Institute of Technology).

\section{APPENDIX 1: SURVEY QUESTIONNAIRE SHEETS}

\section{Questionnaire on disposal of edible food}

This questionnaire asks you about your daily behaviour on food, as well as your experience on food disposal during your part time jobs at food related businesses such as restaurants and supermarkets.

Your responses will be processed statistically, and personal information will not be released. The results will be used for research purposes only. We are grateful to your cooperation to this survey.

In multiple choice questions, please mark with a circle the applicable number. Please fill in the brackets ( ) where applicable. The sheet continues on to the reverse side. This sheet will be collected when completed.

Q1 Let us know about yourself (circle only one)

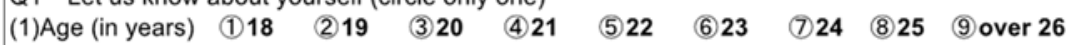

(2)Gender (1) Male (2)Female

Q3 Prefecture you lived the longest before entering university (country in case of foreign students)

Q3 Which of the below describes your housing situation? a.up till high school b.current

(1) housing situation (circle only one applicable for a, and also one for b)

\begin{tabular}{c|c|c|c|c|}
\cline { 2 - 5 } & (1)single & 2)live with family & $\begin{array}{l}\text { (3) live with members } \\
\text { other than family }\end{array}$ & (4) Others (specify) \\
\hline a. Before Uni & & & & \\
\hline b. Current & & & & \\
\hline
\end{tabular}

(2) If you have chosen (2)(live with family) before university, please answer the below:

A. How many members of family did you live with?

Adults(including Grandparents et.al.) ( ) Children (Including yourself) (

B. How many of the above A. (Adults) worked regularly more than 5 days a week? ( )

(3) Regarding Breakfast and Dinner, which applies the most? (choose one each for a. and b.)

\begin{tabular}{|c|c|c|c|c|c|c|}
\hline & $\begin{array}{l}\text { (1) Cook } \\
\text { my own }\end{array}$ & $\begin{array}{l}\text { (2) Someone } \\
\text { cooks for me }\end{array}$ & $\begin{array}{l}\text { (3) Eat } \\
\text { out }\end{array}$ & $\begin{array}{l}\text { (4) bought cooked } \\
\text { items and eat at } \\
\text { home }\end{array}$ & $\begin{array}{l}\text { (5) Do not } \\
\text { eat }\end{array}$ & $\begin{array}{l}\text { (6) Others } \\
\text { Specify }\end{array}$ \\
\hline a.Before Un & & & & & & \\
\hline b.Current & & & & & & \\
\hline a.Before Un & & & & & & \\
\hline b.Current & & & & & & \\
\hline
\end{tabular}

(4) What happens most often regarding lunch? (choose one each for a. and b.)

\begin{tabular}{|c|l|l|l|l|l|}
\cline { 2 - 6 } & $\begin{array}{l}\text { (1)Bring packed } \\
\text { lunch from home }\end{array}$ & $\begin{array}{l}\text { (2)Buy items at } \\
\text { shops /stalls }\end{array}$ & $\begin{array}{l}\text { (3) Eat in } \\
\text { Cafeteria }\end{array}$ & (4)Do not eat & $\begin{array}{l}\text { (5) Others } \\
\text { Specify }\end{array}$ \\
\hline $\begin{array}{c}\text { Lu.Before Uni } \\
\mathrm{h}\end{array}$ & & & & & \\
\hline b.Current & & & & & \\
\hline
\end{tabular}


Q4 With whom did you have meals together, when you were at school age (choose one each for a and b)

\begin{tabular}{|c|c|c|c|c|}
\hline & & $\begin{array}{l}\text { (1) Eat with family or other } \\
\text { co-dwellers }\end{array}$ & (2) Eat alone & Others (specify) \\
\hline & a.Primary/Middle & & & \\
\hline & b.High School & & & \\
\hline$\rightarrow$ & a.Primary/Middle & & & \\
\hline$\rightarrow$ & b.High School & & & \\
\hline
\end{tabular}

Q5 What was the situation regarding not finishing your plate at home? (choose one)

(1) Free to leave anything on plate (2) Supposed to finish everything, but not scolded even if not.

(3) Scolded if not completely finished (4) Others (

Q6 Was there a rule on finishing your plate at school lunches? (Choose one below, referring to your memories during your years at primary school)

(1) No school lunches (2) Free to leave anything on plate (it wasn't regarded as an issue)

(3) Made efforts not to waste food (by adjusting portions and offering seconds) (4) Not allowed to leave anything left on the plate ( must finish given amount of food) (5) Others ( )

Q7 Have you taken up part time jobs now or in the past? (circle only one below)

(1) Food related businesses (Eateries, Food retailers such as Supermarkets, Bakeries, Food processing factories) (2) Anywhere other than (1) (3) Never done part time jobs

If you have selected (20r(3) in the above, skip $Q 8 \sim 10$ and proceed to answer Q11(1) (4) If you have selected [1) (food related)」, continue below

Q8 In what type of shops have you worked (choose all that are applicable)

(1) Eatery (Franchise Chain) (2) Eatery (Independent) (3)Convenience Store (Chainstore)

(4) Small retailer (Independent grocery, bakery etc) (5) Supermarket (Chain)

(6) Supermarket (Independent) (7) Other ( )

Q9 Have you experienced throwing away food, while working at the establishments selected above? (Examples : Throwing away expired items at shops / Throwing away food that customers left on plate)

(1) Yes $\quad$ (2) No

If you have answered (2)(No) in Q9, proceed to Q11 and answer Q11(1) (4)

Q10 For (1) (4)below, please answer about the most memorable workplace for you

(1) Let us know the type (as in Q8) and name of the workplace you have witnessed or were involved in throwing away food

Type of shop as in Q8 $\rightarrow(\quad$ ) Name of establishment (franchise chain) ( )

(2) How long have you worked at this place? (choose one)

(1) less than one week (2) 2 weeks to 3 months (3) 4 to 6 months (4) 7 months to one year (5) more than a year

(3) Have you taken home food that was destined for disposal? (choose one)

(1) Yes almost every time (2) Yes sometimes (3) No (4) Other (

)

continued on reverse 


\begin{tabular}{|c|c|c|c|c|c|c|}
\hline & $\begin{array}{l}\text { (1) } \\
\text { Very much } \\
\text { concerned }\end{array}$ & $\begin{array}{l}\text { Somewhat } \\
\text { concerned }\end{array}$ & $\begin{array}{l}\text { (3) can't } \\
\text { decide }\end{array}$ & $\begin{array}{l}\text { (4) Not } \\
\text { much } \\
\text { concerned }\end{array}$ & $\begin{array}{l}\text { (5) Not } \\
\text { concerned } \\
\text { at all }\end{array}$ & $\begin{array}{l}\text { 6) Not } \\
\text { applicable }\end{array}$ \\
\hline \multicolumn{7}{|c|}{$\begin{array}{l}\text { a.Throwing away items that are } \\
\text { still edible (before expiry date etc) }\end{array}$} \\
\hline \multicolumn{7}{|l|}{$\begin{array}{l}\text { b.Throwing away a large } \\
\text { amount }\end{array}$} \\
\hline \multicolumn{7}{|l|}{$\begin{array}{l}\text { c. Throwing away items still in } \\
\text { package }\end{array}$} \\
\hline \multicolumn{7}{|l|}{$\begin{array}{l}\text { d.What happens to the food } \\
\text { that had been thrown away }\end{array}$} \\
\hline \multicolumn{7}{|l|}{$\begin{array}{l}\text { e. Customers ordering } \\
\text { excessive amount of food }\end{array}$} \\
\hline \multicolumn{7}{|l|}{$\begin{array}{l}\text { f. Policy of throwing away food } \\
\text { at the shop/restaurant }\end{array}$} \\
\hline $\begin{array}{l}\text { g. Costs involved in disposing } \\
\text { food waste }\end{array}$ & & & & & & \\
\hline
\end{tabular}

(5)How did you feel when you first witnessed food disposal at workplace? Choose up to two below
(1) Surprise (2) Sadness (3)Anger
(4) Excitement (5) Happiness (6) Fun
(7) Uneasiness
(8) No emotion
(9) Other (

(6)How do you feel now about throwing away food at your workplace? (Choose One)
(1) No difference from (5)
(2) Stronger feeling than at (5)
(3) Weaker feeling than at (5)
(4) Became indifferent about it

(7)Have your thoughts changed since being involved in throwing away food? (Choose any applicable)

(1) Became less concerned about throwing away food (2) Became more aware about expiry dates

(3) Became more conscious about throwing away food (4) Became more careful about sorting waste (5) Started to perceive food wastage as a social issue (6) No change in attitude (7) Other (

Q11 Please answer the below (1) to (4)

(1)What do you think about the operation of throwing away food at businesses? (Choose one)

(1) Necessary (2) Normal thing to do (3) Should be discouraged (4) Should be prohibited

(2)(1)What are the reasons you chose the answer above? Choose up to three
(1) Staff can take home the leftover food
(2) They are making efforts to reduce food waste
(3) Food waste is utilised as compost etc
(4) Leftover food is provided to NGOs that utilises food to support the homeless et al
(5) It is a rule we need to follow for food hygiene
(6) They are not making enough efforts to reduce food waste
(7) It is ethically wrong (8) Other (

(3) How do you feel about throwing away food at home?

(1) I am against throwing away food that I like

Choose one.

(3) I am against throwing away any food items

(2) I don't mind throwing away food I don't like

(5) Other (

(4) I don't mind throwing away any food items

(4)How do you feel about leaving food on plate at restaurants etc? Choose one.

(1) I am against not finishing food that I like

(2) I don't mind leaving food I don't like

(3) I am against leaving any amount of food

(4) I am against leaving a large amount of food

(5) I don't mind not finishing food (6) It depends on how expensive the meal is (7) Other

\section{REFERENCES}

[1] Think. Eat. Save, Definition of food loss and waste. www.thinkeatsave.org/ index.php/be-informed/definition-of-food-loss-and-waste. Accessed on: 13 Jun. 2018. 
[2] Global Initiative on Food Loss and Waste Reduction, Definitional framework of food loss, 2015.

[3] FAO, Technical platform on the measurement and reduction of food loss and wastefood loss measurement. www.fao.org/platform-food-loss-waste/food-loss/food-lossmeasurement/en/. Accessed on: 13 Jun. 2018.

[4] Tayyib, S. \& Golini, N., The FAO approach to food loss concepts and estimation in the context of Sustainable Development Goal 12 Target 3. Proceedings of the Seventh International Conference on Agricultural Statistics, pp. 576-580, 2016.

[5] EU-FUSIONS, FUSIONS Definitional Framework for Food Waste, 2014.

[6] WRAP UK (Waste and Resources Action Programme), Food and drinks waste in the UK, 2013.

[7] Gennari, P., Indicator 12.3.1: Global Food Loss Index, 3rd meeting of the IAEGSDGs. https://unstats.un.org/sdgs/meetings/iaeg-sdgs-meeting-03. Accessed on: 13 Jun. 2018.

[8] United Nations, Sustainable Development Goals. www.un.org/sustainabledevelopment/sustainable-development-goals/. Accessed on: 13 Jun. 2018.

[9] United Nations, Tier Classification for Global SDG Indicators. https://unstats.un.org/sdgs/iaeg-sdgs/tier-classification/. Accessed on: 13 Jun. 2018.

[10] MAFF (Ministry of Agriculture Forestry and Fishery), Report on the utilisation of food waste (2014 estimates). www.maff.go.jp/j/shokusan/recycle/syoku_loss/attach/pdf/ 161227 4-11.pdf. Accessed on: 13 Jun. 2018.

[11] Takatsuki, H., Waste Problems and Lifestyles, Nippon Hyoron Sha, 2004.

[12] Toyo Keizai, Restaurant chains in trouble, not enough part-time workers, Shukan Toyo Keizai, p. 43. Accessed on: 6 Dec. 2014.

[13] Jun Ltd, Survey on university student's part-time job wages. https://genkibaito.jp/ arubaito/collegebaito-money/. Accessed on: 13 Jun. 2018.

[14] Stuart, T., Waste: Uncovering the Global Food Scandal, Penguin: London, 2009.

[15] Kreuzberger, S. \& Thurn, V., Die Essensvernichter, Kiepenheuer \& Witsch, 2012.

[16] Nakahara, Y., Research on the reduction of food waste - survey on university students' attitudes to food disposal). BA dissertation, Taisho University, 2015.

[17] Fukuoka, M., Fujikura, M., Hanashima, A. \& Okayama, T., Food waste disposal on part-time jobs for university students. Proceedings, Japan Society of Material Cycles and Waste Management, 27, pp. 55-56, 2016.

[18] Principato, L., Secondi, L. \& Pratesi, C.A., Reducing food waste: an investigation on the behaviour of Italian youths. British Food Journal, 117(2), pp. 731-748, 2015. DOI: $10.1108 / \mathrm{bfj}-10-2013-0314$.

[19] Clark, J. \& Manning, L., What are the factors that an opportunity sample of UK students insinuate as being associated with their wastage of food in the home setting? Resources, Conservation and Recycling, 130, pp. 20-30, 2018.

DOI: 10.1016/j.resconrec.2017.11.005.

[20] Tange, H., Operation zero leftovers" started with listening to the farmers. Journal of Japan Society of Waste Management, 19, pp. 72-79, 2008.

[21] Yamakawa, H., Thoughts on cyclical society and dietary customs through food education. Journal of Japan Society of Waste Management, 19, p. 103, 2008.

[22] Schneider, F., The evolution of food donation with respect to waste prevention. Waste Management, 33(3), pp. 755-763, 2013. DOI: 10.1016/j.wasman.2012.10.025. 